\title{
Application of the Taguchi method to improve a medical device cutting process
}

\author{
Jorge Limon-Romero ${ }^{1} \cdot$ Diego Tlapa $^{1}$ • Yolanda Baez-Lopez ${ }^{1}$. \\ Aide Maldonado-Macias ${ }^{2} \cdot$ Leonardo Rivera-Cadavid $^{3}$
}

Received: 23 November 2015 / Accepted: 13 March 2016/Published online: 16 April 2016

(C) The Author(s) 2016. This article is published with open access at Springerlink.com

\begin{abstract}
Companies currently are immersed in a highly competitive world; therefore, they must adopt continuous process and product improvement techniques to remain in business and retain loyal customers. This paper presents the analysis of a medical device manufacturing company to determine what factors influence the length variation of plastic tubes in a cutting process. These tubes are part of intensive care sets; therefore, their length and diameter are critical features. Recently, products were rejected for not meeting the tube length specification, causing customer complaints regarding product quality. The Taguchi method was applied to find significant factors that determine the best configuration in the cutting process to approximate this quality characteristic to its desired target value. Important factors and their corresponding best levels were identified. After the proposed process adjustment was implemented, the process capability in$\operatorname{dex}\left(\mathrm{C}_{\mathrm{pk}}\right)$ increased from 0.90 to 1.58 , which indicated a considerable reduction in customer complaints and corresponding costs.
\end{abstract}

Jorge Limon-Romero

jorge.limon@uabc.edu.mx

1 Facultad de Ingeniería, Arquitectura y Diseño, Universidad Autónoma de Baja California, Carretera transpenisular Ensenada-Tijuana 3917, Colonia Playitas, zip code 22860 Ensenada, Baja California, Mexico

2 Department of Industrial and Manufacturing Engineering, Universidad Autónoma de Ciudad Juarez, Ave. del Charro 450 Norte, zip code 32310 Cd Juarez, Chihuahua, Mexico

3 School of Industrial Engineering, Universidad del Valle, Ciudad Universitaria Meléndez, Calle 13 No 100-00, Cali, Colombia
Keywords Taguchi method $\cdot$ Cutting process $\cdot$ Medical device $\cdot$ Capability improvement

\section{Introduction}

One of the main aspects that determine market permanence for any business is its quality level, which is directly related to customer satisfaction. The quality of products and services helps to obtain customer loyalty, thus increasing the possibility of future business. Strong competition demands a high level of quality [1]. Thus, it is important for organizations to continually improve the quality level of products and services to remain competitive in the marketplace. For this reason, the continuous improvement of process and product quality levels is an important issue. Several strategies, such as Six Sigma (SS), have emerged to achieve this quality improvement. SS strategy as a fundamental matter to understand customer and market needs, using certain data to drive both strategy and action to improve the basic processes [2]. The objective of SS is to achieve high performance, reliability, and benefit to the customer or end consumer of the company. The ways organizations have evolved through continuous improvement initiatives to increase customer satisfaction and lower operational costs have been evident throughout the last few decades [3]. The changes in the way companies offer their products and/or services, driven by technological changes, have led to the need to develop new processes to ensure the proper management of activities within firms, aiming to provide the highest possible customer satisfaction level [4]. 


\section{Problem presented by this manufacturing company}

From this perspective, the medical industry is no exception; its products are aimed at people and are directly related to their health and integrity. The medical manufacturing company referred to in this study employs a process related to the cutting of tubes with lengths determined by the type or configuration of the product, mainly intravenous therapy products. The lengths and internal diameters of the tubes in this type of product affect the main flow of drugs administered through them; thus, a variation in these dimensions may significantly affect the patient and therefore is critical to ensure the accuracy of the tube cutting process. Recently, some tube lots have been rejected due to their lengths not meeting specifications. The methodology section will further describe this problem that the company experiences.

\section{Experimental procedure}

Experimental design is a strategy of planning, conducting, analyzing, and interpreting experiments so that sound and valid conclusions can be drawn efficiently, effectively, and economically. This strategy provides the experimenters with a greater understanding and power over the experimental process [5]. Experimental design is an essential tool for studying complex systems, and it is the only rigorous replacement for the inferior but unfortunately still common practice of studying one variable at a time [6].

The Taguchi method for experimental design is a powerful problem-solving technique for improving process performance, yield and productivity [7]. It can reduce scrap rates, rework costs, and manufacturing costs due to excessive variability in processes. The Taguchi experimental design aims to minimize the variability in a product or operation in line with a specific function by selecting the most suitable combinations of the controllable factor levels compared to the uncontrollable factors that create variability for a specific product or operation [8]; in this sense, Taguchi parameter design or robust design methodology involves the maximization of performance and quality at minimum cost [9]. This is fundamentally achieved by determining the best settings of those design or process parameters that influence the product performance variation and by fine-tuning those design or process parameters that influence the average performance.

The essential concept of the Taguchi quality method is the definition of a loss function for a particular production process, calculated by evaluating equivalent signal-to-noiseratios (SNRs), defined as the ratios between the magnitude of a process mean and its variation; this allows the best solutions to a problem to be defined as those leading to maximum SNRs and minimum values of the loss functions [10].

Toward the end of World War II, Dr. Genichi Taguchi conducted extensive research using experimental design techniques. In addition to a new approach to quality improvement, his major contribution was developing and using a special set of orthogonal arrays (OAs) for designing experiments. OAs are a set of tables of numbers, each of which can be used to present experiments for a number of experimental situations. Use of these arrays for design experiments is the key to learning the design of experiments through the Taguchi approach. Today, when one wants to learn the Taguchi experimental technique, it is a requirement to learn how to use OAs in the way that Taguchi prescribed [11]. Furthermore, OAs are used to estimate the effects of several factors and the effect of interactions by minimizing the number of experiments [12]. Utilizing the Taguchi OA concept, Gu et al. [13] showed that the number of experiments can be significantly reduced, and thus, the time and cost caused by multiple experiments are also reduced. For example, Inei-Shizukawa et al. [14] utilized a Taguchi approach with seven factors for ethanol yield at two levels with an OA layout of $\mathrm{L}_{8}\left(2^{7}\right)$ designed to minimize the number of experiments. Rico et al. [15] analyzed the effect of the side cutting edge angle on the surface roughness through a Taguchi $\mathrm{L}_{32}$ using two replicates.

Another important component of the Taguchi method is the SNR, which is a measurement scale that has been used in the communication industry for nearly a century. A radio measures the signal of the wave of voice transmitted from a broadcasting station and converts the wave into sound. Taguchi generalized the concept of the SNR as used in the communication industry and applied it to the
Fig. 1 Pareto analysis of nonconforming lot reports

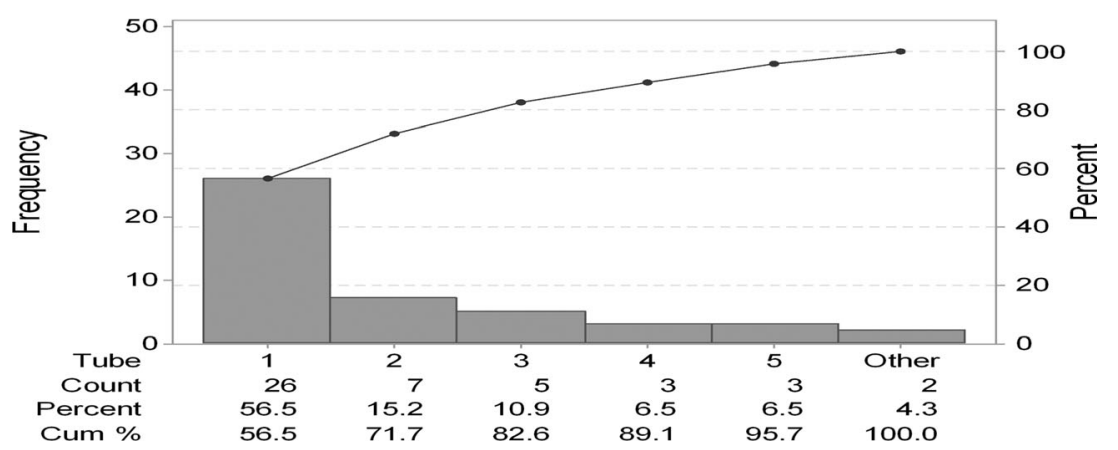


Table 1 Data collected for tube length before the Taguchi analysis

\begin{tabular}{lllll}
\hline 106.563 & 105.563 & 106.313 & 105.750 & 106.250 \\
105.625 & 105.938 & 105.688 & 105.563 & 106.055 \\
105.500 & 105.875 & 106.313 & 105.313 & 105.938 \\
105.563 & 105.438 & 106.000 & 105.625 & 105.688 \\
106.375 & 105.750 & 105.500 & 105.938 & 105.375 \\
105.375 & 105.750 & 105.563 & 105.625 & 105.062 \\
105.372 & 105.188 & 105.625 & 105.313 & 105.188 \\
105.500 & 105.875 & 105.688 & 105.938 & 105.188 \\
105.563 & 105.625 & 105.688 & 105.375 & 106.055 \\
105.813 & 106.055 & 105.313 & 105.625 & 105.375 \\
\hline
\end{tabular}

evaluation of measurement systems as well as to the function of products and processes. A higher SNR indicates higher quality [16]. In the Taguchi method, quality characteristics can be categorized into the three following types: the lower the better, the nominal the better, and the higher the better [5]. The equations utilized to calculate the SNR according to the aforementioned scenarios are as follows (Eqs. 1, 2, and 3):

The lower the better

$$
S N=-10 * \log _{10}\left(\frac{1}{n} \sum_{i=1}^{n} y_{i}^{2}\right)
$$

The nominal the better

$$
S N=10 * \log _{10}\left(\frac{\bar{Y}^{2}}{S^{2}}\right)
$$

The higher the better

$$
S N=-10 * \log _{10}\left(\frac{1}{n} \sum_{i=1}^{n} \frac{1}{y_{i}^{2}}\right)
$$

The process of performing a Taguchi experiment follows a number of distinct steps [7]:
Step 1: formulation of the problem - the success of any experiment is dependent on a complete understanding of the nature of the problem.

Step 2: identification of the output performance characteristics most relevant to the problem.

Step 3: identification of control factors, noise factors, and signal factors (if any).

Step 4: selection of factor levels, possible interactions, and the degrees of freedom associated with each factor and the interaction effects.

Step 5: design of an appropriate OA.

Step 6: preparation of the experiment.

Step 7: running the experiment with appropriate data collection.

Step 8: statistical analysis and interpretation of experimental results.

Step 9: undertaking a confirmatory run of the experiment.

\section{Development of the study}

The Taguchi method was used in the experiment to determine the best operation conditions of the process that reduce length variability in the cut tubes at its maximum and also approximate the average dimension to the objective value. This method was employed due to its flexibility and speed to obtain the results needed, since the goal was to address the client's complaint as soon as possible. Therefore, the experiment in this manufacturing company was carried out based on the aforementioned steps as shown below.

\section{Step 1: Problem formulation}

In the cutting process, six different types of plastic tubes are used to feed a cutting machine; however, as shown in Fig. 1, tube type 1 represents near $60 \%$ of the non-conforming lot reports (26 of 46) with a cost of US\$290 each, which means that several thousands of dollars are lost monthly.

Step 2: Identification of the output performance characteristics most relevant to the problem
Fig. 2 Normality test for the data before improvement

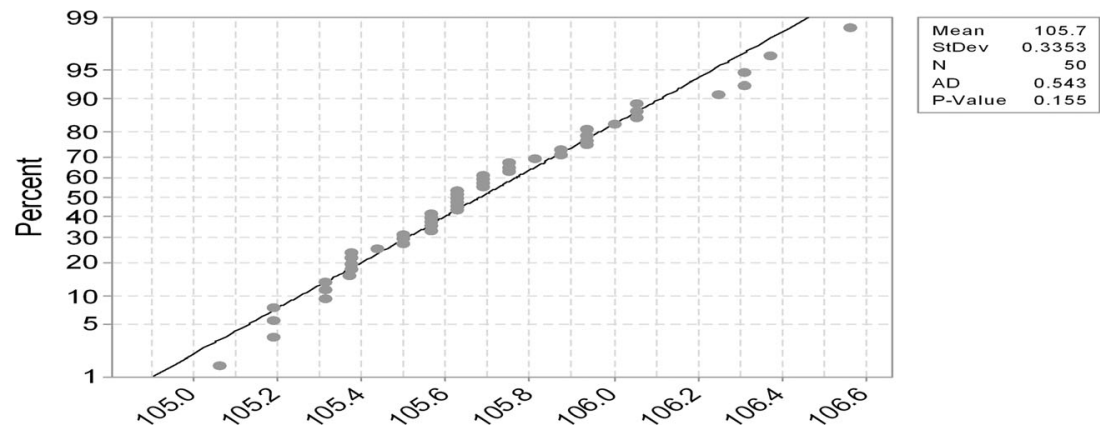


Fig. 3 Capability analysis before improvement

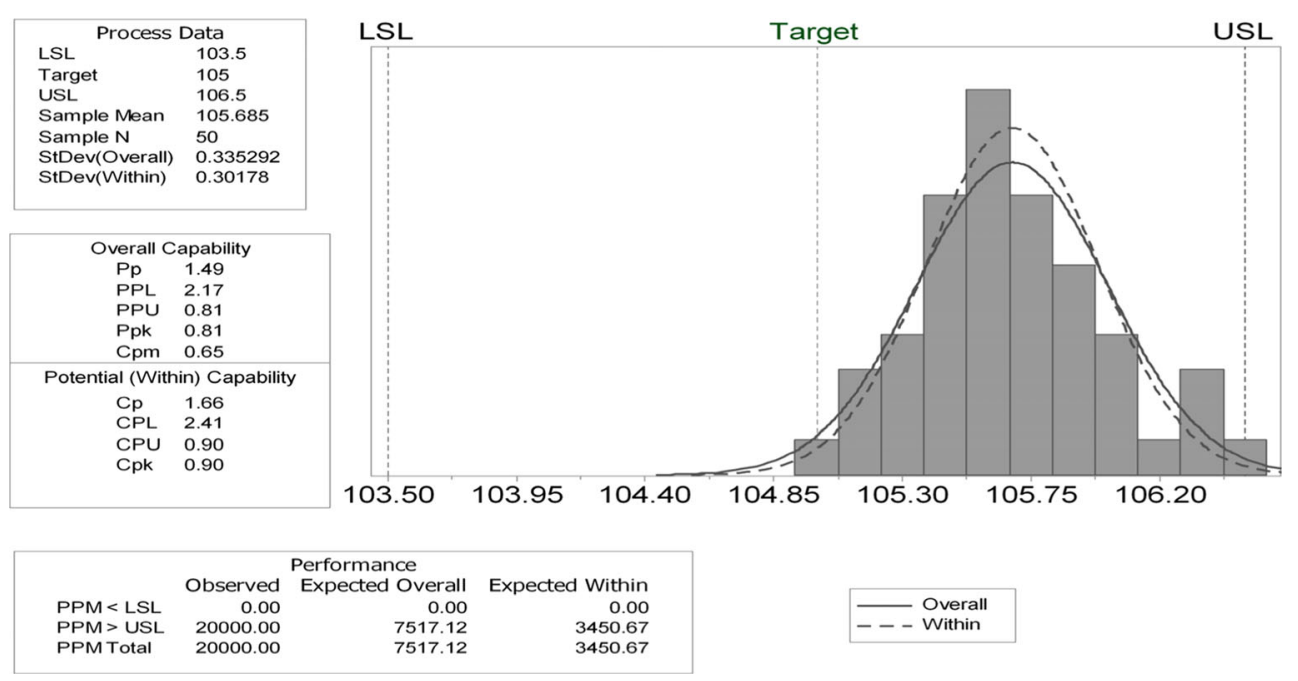

After identifying the main product with rejected lots, it was necessary to identify the main causes of quality rejection. In this case, the most relevant characteristic was tube length because some products were out of specification, and this dimension is crucial to the security of users. Once the rejection cause was determined, a capability analysis for the quality characteristic was performed using the Minitab 17 software to evaluate the initial situation by cutting 50 tubes using the current process setup and considering a specification of $150 \pm 1.5$ in as shown in Table 1 . The normality of the data was tested previously to calculate the capability index. The normality results and capability analysis are shown in Figs. 2 and 3, respectively. This analysis made evident the necessity to improve the process involved with tube 1 cutting because the $\mathrm{C}_{\mathrm{pk}}$ index is smaller than one, which is unacceptable. Figure 3 shows that the basic problem is that the process mean is located far from the target value; however, this could potentially be a good process if its mean moves toward the center of specification.

Step 3: Identification of control factors, noise factors, and signal factors (if any)

To determine the factors to be analyzed, previous runs were performed, and a brainstorming session with machine operators and maintenance personnel was executed. The ideas generated are represented on the cause and effect diagram in Fig. 4, from which wrong machine parameters were selected as the main cause to be more broadly studied.

Step 4: Selection of factor levels, possible interactions, and degrees of freedom associated with each factor and the interaction effects

Although the process parameters for cutting the tubes are well-established, these adjustments are occasionally modified depending on the experience of each operator. In fact, when operators detected a tube out of specification, they modified the process setup based on their experience. The possible machine parameters and their possible levels as well as which of them will be more broadly studied are shown in Table 2. To determine which parameters must be considered for further analysis, the opinion of the operators and maintenance department were considered. Additionally, some previous runs were tested.

In addition to the factors in Table 2, the conversion factor was incorporated because the machine was designed to work in millimeters and the specification for the product is in inches. Operators must

Fig. 4 Cause and effect diagram

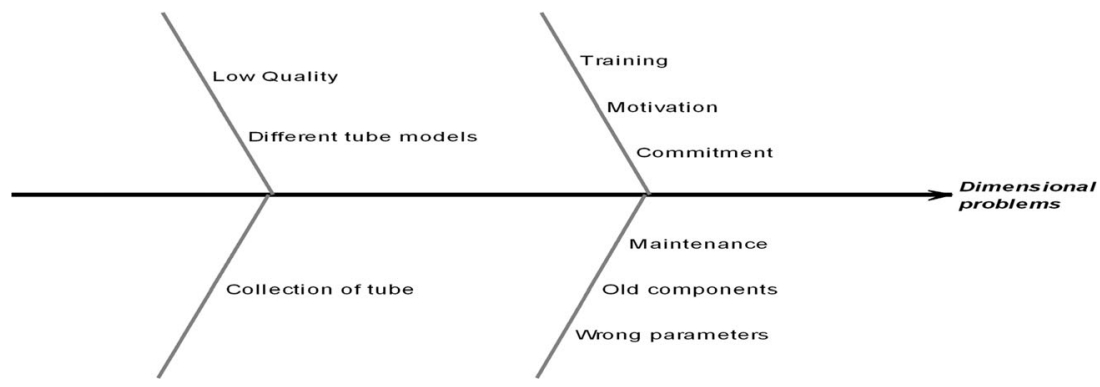


Table 2 Machine parameters and associated levels to be studied

\begin{tabular}{llll}
\hline Parameter & Possible levels & Decision & Selected levels \\
\hline ACC & 4 & Important & 2 \\
Feed rate & 4 & Important & 2 \\
Brake pressure & 4 & Not important & - \\
Air pressure & 5 & Not important & - \\
Speed controller & 5 & Important & 2 \\
\hline
\end{tabular}

perform the conversion every time they change the part number. Although the equivalence from millimeters to inches is well known ( 1 in $=25.4 \mathrm{~mm}$ ), some discrepancy is present in the machine, so this equivalence does not work properly. This factor was introduced at four levels.

Step 5: Design of an appropriate orthogonal array (OA)

First, the original $\mathrm{L}_{8}\left(2^{7}\right) \mathrm{OA}$, had to be modified to accommodate one factor at four levels and three more factors at two levels. To do this, the triangular matrix corresponding to this OA was used. It is possible to appreciate in this triangular matrix, so columns 1, 2, and 3, each with one degree of freedom, are related. For this reason, these columns can be grouped into only one column, resulting a column with three degrees of freedom to accommodate one factor at four levels.

Step 6: Preparation of the experiment

The experimental matrix with real values for each factor is shown in Table 3.

Step 7: Running the experiment with the appropriate data collection

The cutting machine has five parallel cavities and cuts five tubes at once. Due to this, the first task before running the experiment was to investigate whether these cavities represented an important source of variation. For this reason, an analysis of variance (ANOVA) with this factor was completed, and the analysis of the results demonstrated that the

Table 3 Real levels for factors to be analyzed

\begin{tabular}{lllll}
\hline Run & Factor of conversion & ACC & Feed rate & Speed controller \\
\hline 1 & 25.4 & 3 & 3 & 70 \\
2 & 25.4 & 5 & 5 & 100 \\
3 & 26.1 & 3 & 3 & 100 \\
4 & 26.1 & 5 & 5 & 70 \\
5 & 26.8 & 3 & 5 & 70 \\
6 & 26.8 & 5 & 3 & 100 \\
7 & 27.5 & 3 & 5 & 100 \\
8 & 27.5 & 5 & 3 & 70 \\
\hline
\end{tabular}

Table 4 Experimental results for the tube length

\begin{tabular}{llllll}
\hline Run & \multicolumn{5}{l}{ Replicates } \\
\cline { 2 - 6 } & 1 & 2 & 3 & 4 & 5 \\
\hline 1 & 102.375 & 101.875 & 102.500 & 102.875 & 103.625 \\
2 & 102.688 & 102.375 & 103.875 & 103.063 & 103.625 \\
3 & 105.875 & 105.563 & 106.875 & 105.688 & 106.063 \\
4 & 105.875 & 105.250 & 106.500 & 105.375 & 105.563 \\
5 & 108.875 & 108.063 & 109.313 & 108.188 & 108.750 \\
6 & 108.750 & 108.375 & 108.438 & 108.750 & 108.375 \\
7 & 111.056 & 110.625 & 110.875 & 111.056 & 111.375 \\
8 & 111.313 & 110.875 & 110.750 & 110.875 & 110.500 \\
\hline
\end{tabular}

cavities do not differ significantly; therefore, the experiment was conducted in only one cavity to avoid wasting material. Cavity number three was chosen, and the experiment was conducted with five replicates. The experimental results are shown in Table 4.

Step 8: Statistical analysis and interpretation of experimental results

The mean and SNR are calculated for further analysis using the nominal the better case according to Eq. (2), as shown in Table 5. Later, with these values, factorial plots for the mean and SNR were built, as seen in Figs. 5 and 6, respectively. With these plots, the experimenter determined which level for every factor represents the best choice to achieve a certain result about the mean response and robustness.

The factorial plot for the means is shown in Fig. 5 and was used to determine that the most important factor was conversion. Furthermore, knowing that the target value for this tube is $105.0 \mathrm{in}$. the value of 26.1 was chosen; for ACC, the feed rate and speed controller must be fixed depending on practical or economic reasons because their slopes are nearly zero or are graphically insignificant. In the same manner, from the factorial plot for the SNR in Fig. 6, the best value for conversion, $\mathrm{ACC}$, feed rate, and speed
Table 5 Mean and SNR results

\begin{tabular}{lll}
\hline Run & Mean & SNR \\
\hline 1 & 102.650 & 43.943 \\
2 & 103.125 & 44.329 \\
3 & 106.013 & 46.222 \\
4 & 105.713 & 46.517 \\
5 & 108.638 & 46.497 \\
6 & 108.538 & 54.884 \\
7 & 110.997 & 52.110 \\
8 & 110.863 & 51.508 \\
\hline
\end{tabular}


Fig. 5 Factorial plot for mean response

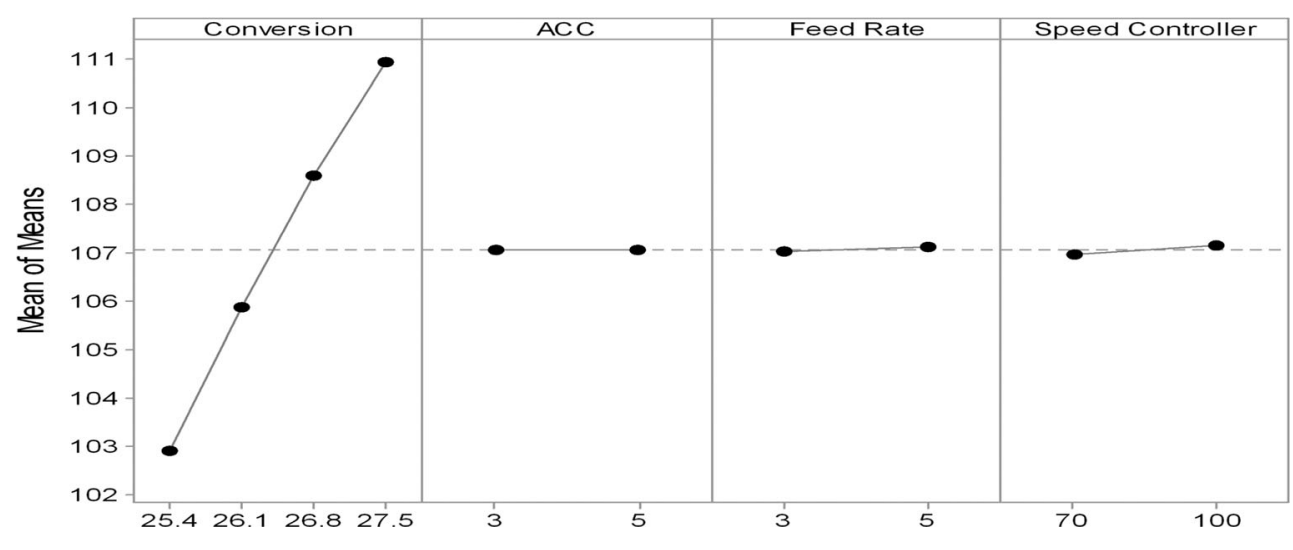

controller are $27.5,5,3$, and 100, respectively, for robustness; although, according to the ANOVA, these values were not significant. The results of the ANOVA for the mean and SNR are listed in Tables 6 and 7 , respectively. Table 8 contains the proposed levels for the analyzed factors according to the mean and SNR analysis. The table also shows the final decision for the process-operating condition.

Step 9: Undertaking a confirmatory run of the experiment

After determining the best adjustment of the cutting machine, a confirmatory run was performed using the final levels shown in Table 8 . As previously explained, 26.1 was considered as the appropriate level for the conversion factor, since, as Fig. 5 shows, it allows for the best approximation to the objective value, which is 105 in. As for ACC, feed rate, and speed controller, the level considered was the one repeated in both responses, since none of them represents a practical advantage over the other. With the aim of calculating the $\mathrm{C}_{\mathrm{pk}}$ index, 50 tubes were cut and measured for this proposed process setup, and the results are presented in Table 9. First, the data normality was tested using the Anderson-Darling test, and with $P=0.482$, the hypothesis of normality was accepted (Fig. 7). Thus, the capability analysis was performed, and a $\mathrm{C}_{\mathrm{pk}}$ index equal to 1.58 was obtained, as shown in Fig. 8. These results prove that the proposed setup is better than the initial setup, with a mean closer to the target value and a standard deviation slightly smaller. Additionally, a control chart was built for the new process and was established to monitor and control the future production of this tube, as shown in Fig. 9.

\section{Discussion}

In this paper, the length variation in a tube cutting process is addressed by conducting an application of Taguchi methods for optimizing a tube cutting process. Only the parameter factor of conversion was significant. Therefore, to achieve a target value of $105.0 \mathrm{in}$. the conversion factor must be 26.1. In addition, for ACC, the feed rate and speed controller could be used depending on practical or economic reasons; however, specific levels were chosen in this case. It is important to highlight the advantage of addressing these problems using designed experiments regardless of whether it is achieved by the classical or

Fig. 6 Factorial plot for the SNR

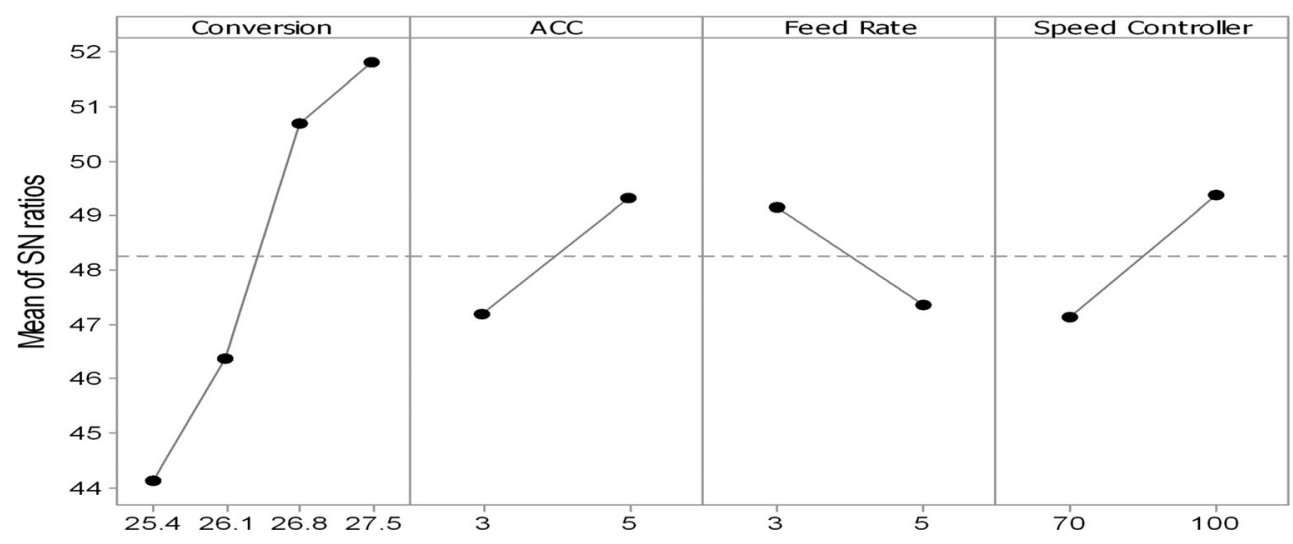


Table 6 Analysis of variance for the means

\begin{tabular}{llrlll}
\hline Source & DF & SeqSS & AdjMS & F & $P$ \\
\hline Conversion & 3 & 72.305 & 24.102 & 351.84 & 0.039 \\
ACC & 1 & 0.000 & 0.000 & 0.01 & 0.949 \\
Feed rate & 1 & 0.021 & 0.021 & 0.31 & 0.678 \\
Speed controller & 1 & 0.082 & 0.082 & 1.20 & 0.471 \\
Error & 1 & 0.069 & 0.069 & & \\
Total & 7 & 72.477 & & & \\
\hline
\end{tabular}

Taguchi approach, although as previously mentioned, one advantage of the Taguchi method is that it can use fewer experimental runs due to the proposed use of orthogonal arrays. In many companies in Latin America, these techniques remain unknown, and product and process improvement is addressed by trial and error or by using one factor at a time. These methods often cause the improvements to not be as successful as expected, resulting in the loss of business opportunities caused by the excessive product costs from low quality and inefficient processes. Some reasons for low implementation of design of experiments and, in particular, of the Taguchi method of experimental design in manufacturing sector follow, as stated by Antony et al. [9]:

- Inadequate education in applied quality improvement methods and strategies at the university level.

- Manager familiarity with home-grown solutions (generally one factor at a time approach) for process and design optimization problems.

- Lack of understanding of the benefits of the Taguchi method of experimental design for addressing real-world problems in organizations.

- Lack of communication and collaboration between academic and industrial fraternities.

- Incorrect perceptions that experimentation requires massive resources and is always expensive to execute.

- Poor attitudes toward experimental design and the associated strategies.

Table 7 Analysis of variance for the SNR

\begin{tabular}{llrlll}
\hline Source & DF & \multicolumn{1}{c}{ SeqSS } & AdjMS & \multicolumn{1}{l}{ F } & $P$ \\
\hline Conversion & 3 & 78.230 & 26.077 & 2.64 & 0.418 \\
ACC & 1 & 8.966 & 8.966 & 0.91 & 0.516 \\
Feed rate & 1 & 6.313 & 6.313 & 0.64 & 0.571 \\
Speed controller & 1 & 10.286 & 10.286 & 1.04 & 0.494 \\
Error & 1 & 9.891 & 9.891 & & \\
Total & 7 & 113.686 & & & \\
\hline
\end{tabular}

Table 8 Best levels and final decision for the analyzed factors

\begin{tabular}{lllll}
\hline Analysis & Conversion & ACC & Feed rate & Speed controller \\
\hline Mean & 26.1 & 3 or 5 & 3 or 5 & 70 or 100 \\
SN & 27.5 & 5 & 3 & 100 \\
Final & 26.1 & 5 & 3 & 100 \\
\hline
\end{tabular}

Consequently, the challenge is to continue performing these kinds of application projects that help businesses learn to utilize useful statistical tools for process improvement and experimental design. The literature provides a vast amount of actual practical problems solved using experiments designed by the classical or Taguchi approaches, such as in [17-23]. A better understanding of both alternatives can be achieved consulting to Taguchi et al. [16] and Montgomery [24]. Recently, while attempting to make the Taguchi method more flexible and powerful, some studies proposed the use of this experimental alternative with such artificial intelligence techniques as neural networks, fuzzy logic, and genetic algorithms to optimize products and processes [25-30].

\section{Conclusions}

Statistically designed experiments are a powerful tool for optimizing systems. The Taguchi approach was applied in this work to determine the best configuration of a plastic tube cutting process in a medical manufacturing company. The application of the Taguchi method was a novel option for the engineers of this company to conduct process improvement; it resulted in a complete process change compared with their previously established method. Performing this experiment with the methodology they typically implemented would have required more than $32,000 \mathrm{~m}$ of tubing, compared to approximately $107 \mathrm{~m}$ that were needed in this experiment (nearly 300 times less material), which entailed

Table 9 Data collected for tube length after the Taguchi analysis

\begin{tabular}{lllll}
\hline 105.375 & 105.500 & 105.063 & 104.630 & 105.055 \\
105.630 & 105.250 & 105.688 & 104.875 & 105.438 \\
105.375 & 104.875 & 105.688 & 104.813 & 105.000 \\
105.563 & 105.063 & 105.063 & 105.313 & 105.375 \\
105.313 & 105.056 & 105.313 & 105.250 & 105.630 \\
105.210 & 105.813 & 105.188 & 105.188 & 104.813 \\
105.375 & 104.813 & 104.938 & 105.055 & 105.438 \\
105.375 & 105.063 & 104.750 & 105.063 & 105.250 \\
105.250 & 105.438 & 105.563 & 104.750 & 105.563 \\
105.063 & 105.188 & 105.250 & 104.688 & 105.055 \\
\hline
\end{tabular}


Fig. 7 Normality test for the data after improvement

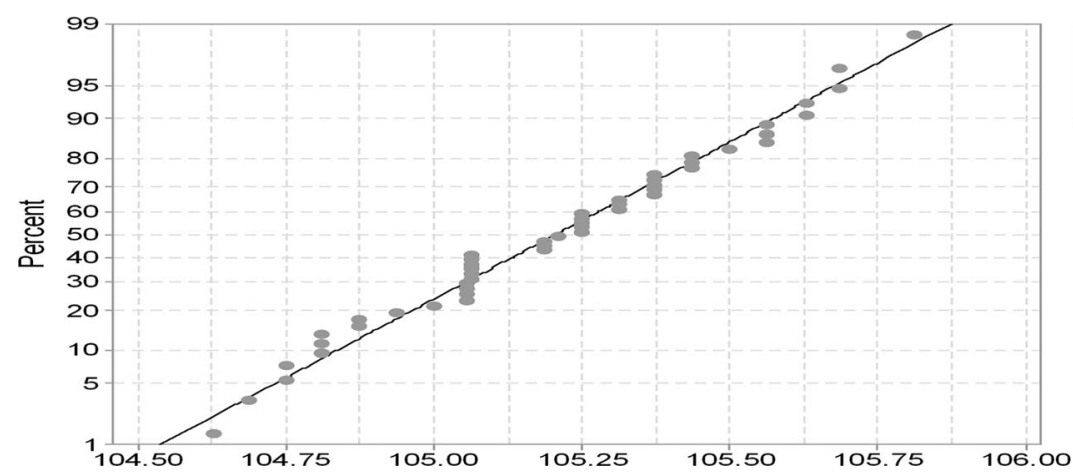

$\begin{array}{lr}\text { Mean } & 105.2 \\ \text { StDev } & 0.2870\end{array}$ N $\quad 50$ $\begin{array}{ll}A D & 0.341 \\ P-V a l u e & 0.482\end{array}$
Fig. 8 Capability analysis after improvement

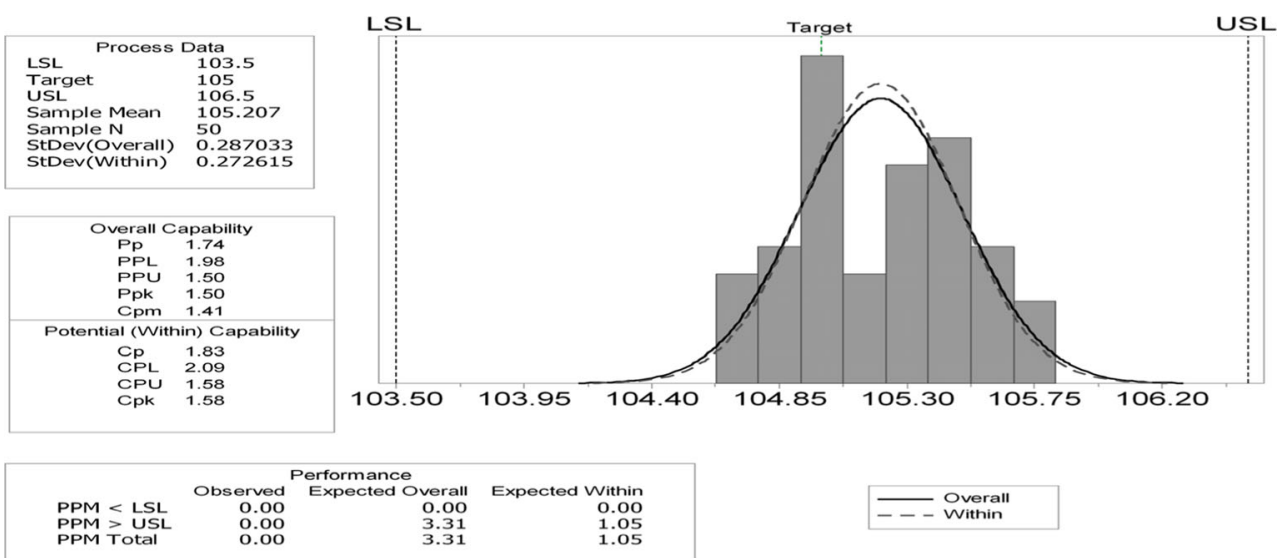

a reduction in equipment operating and personnel costs for those involved in the collection and measurement of tubes during the experiment. Of course, a reduction in the environmental impact due to the reduction in plastic material waste was also realized. Through a confirmatory run with the new process established, it was possible to validate the impact of this project, demonstrating that the capability index $\mathrm{C}_{\mathrm{pk}}$ of the process increased significantly from 0.90 to 1.58 , which represented significant savings and a reduction of customer complaints. Additionally, no additional costs were required to implement the proposed processoperating condition.
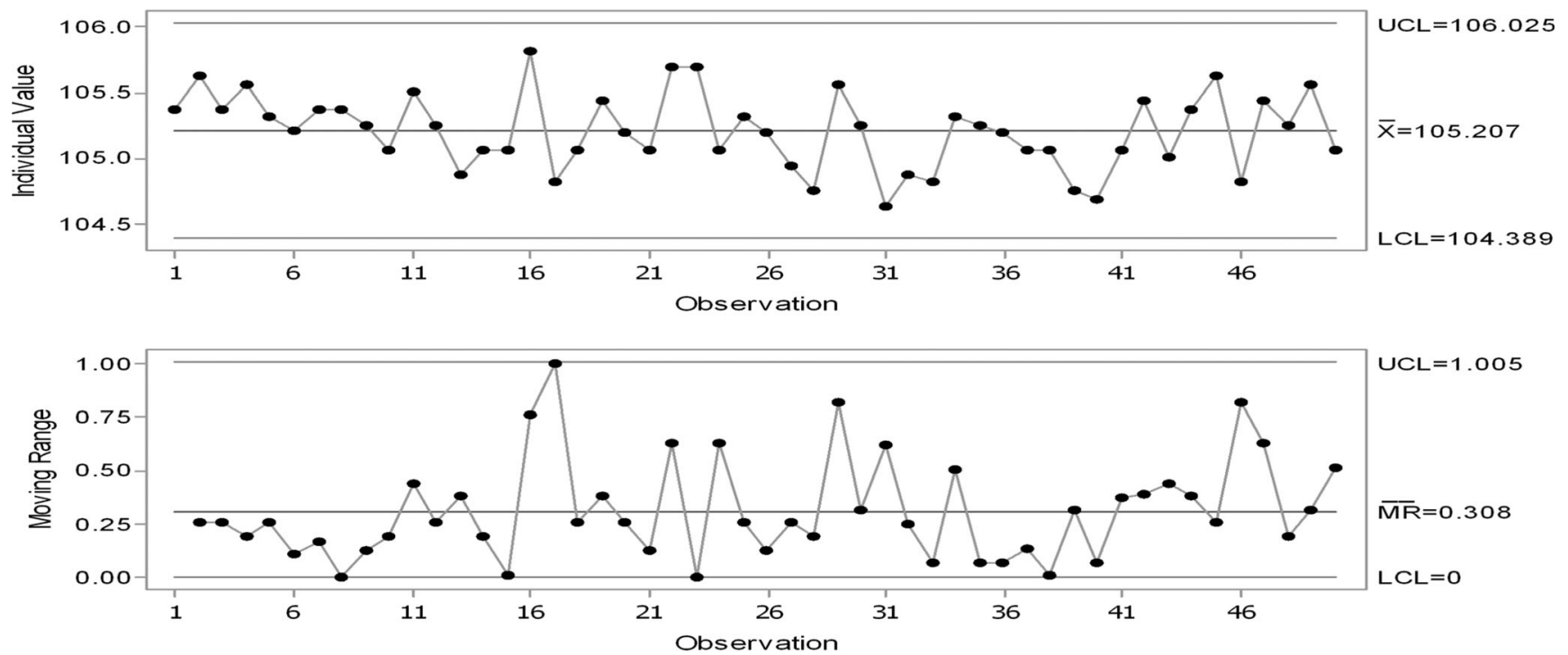

Fig. 9 Control chart to monitor future production 
Acknowledgments The authors thank the Mexican National Council for Science and Technology (CONACyT) for the economic support through the Industrial Process Optimization network with number 242104.

Open Access This article is distributed under the terms of the Creative Commons Attribution 4.0 International License (http:// creativecommons.org/licenses/by/4.0/), which permits unrestricted use, distribution, and reproduction in any medium, provided you give appropriate credit to the original author(s) and the source, provide a link to the Creative Commons license, and indicate if changes were made.

\section{References}

1. Escanciano C, Iglesias F (2012) Quality management and integrated total quality in Spanish mining: results of an empirical study. DYNA 171:167-174

2. Sitnikov C (2012) Six sigma as a strategic tool for companies. Young Econ J Rev Tinerilor Econ 19:94-102

3. Vijaya SM (2013) Synergies of lean six sigma. IUP J Oper Manag 1:21-31

4. Gil-Gómez H, Oltra-Badenes R, Adarme-Jaimes W (2014) Service quality management based on the application of the ITIL standard. DYNA 186:51-56. http://dx.doi.org/10.15446/dyna.v81n186. 37953

5. Antony J, Capon N (1998) Teaching experimental design techniques to industrial engineers. Int J Eng Educ 5:335-343. doi:10. $1108 / 00438020110391873$

6. Mathews PG (2005) Design of experiments with Minitab; ASQ Quality press. Milwaukee, USA

7. Antony J, Antony FJ (2001) Teaching the Taguchi method to industrial engineers. Work Study 4:141-149. doi:10.1108/ 00438020110391873

8. Peker M, Sen B, Kumru PY (2012) An efficient solving of the traveling salesman problem: the ant colony system having parameters optimized by the Taguchi method. Turkish J Electric Eng Comput Sci 1:2015-2036. doi:10.3906/elk-1109-44

9. Antony J, Perry D, Wang C, Kumar M (2006) An application of Taguchi method experimental design for new product design and development process. Assem Autom 1:18-24. doi:10.1108/ 01445150610645611

10. Agastra E, Pelosi G, Selleri S, Taddei R (2013) Taguchi's method for multi-objective optimization problems. Int J RF Microwave Comput Aided Eng 3:357-366. doi:10.1002/mmce.20680

11. Roy RK (2001) Design of experiments using the Taguchi approach: 16 steps to product and process improvement. John Wiley \& Sons Inc, New York, USA

12. Taguchi G, Jugulum R (2002) The Mahalanobis-Taguchi strategy: a pattern technology system. John Wiley \& Sons, New York, USA

13. Gu F, Hall P, Miles NJ, Ding Q, Wu T (2014) Improvement of mechanical properties of recycled plastic blends via optimizing processing parameters using the Taguchi method and principal component analysis. Mater Des 62:189-198. doi:10.1016/j. matdes.2014.05.013

14. Inei-Shizukawa G, Velasco-Bedrán HA, Gutiérrez-López GF, Hernández-Sánchez H (2009) Statistical approach to optimization of ethanol fermentation by saccharomyces cerevisiae in the presence of Valfor® 100 Zeolite Naa. Revista de Ingeniería Química 3: 265-270

15. Rico L, Noriega S, Garcia JL, Martinez EA, Neco R, Estrada FJ (2010) Effect of the side cutting-edge angle on the surface roughness for aluminum 1350 in the turning operation by Taguchi method. J Appl Res Technol 3:395-405

16. Taguchi G, Chowdhury S, Wu Y (2005) Taguchi's quality engineering handbook. John Wiley \& Sons, New Jersey, USA

17. Akbarzadeh A, Kouravand S, Imani B (2013) Robust design of a bimetallic micro thermal sensor using Taguchi method. J Optim Theory Appl 1:188-198. doi:10.1007/s10957-012-0171-x

18. Ramkumar R, Ragupathy A (2013) Optimization of cooling tower performance analysis using Taguchi method. Therm Sci 2:457-470. doi:10.2298/TSCI110528024R

19. Senthilkumar N, Ganapathy T, Tamizharasan T (2014) Optimization of machining and geometrical parameters in turning process using Taguchi method. Aust J Mech Eng 2:233-246

20. Deniz F (2013) Optimization of biosorption conditions for color removal by Taguchi DOE methodology. Environmental Progress and Sustainable Energy 32(4):1129-1133. doi:10.1002/ep.11740

21. KoonChun L, SooKing L, Pehchiong T (2015) Optimization of electrostatic separation process for maximizing biowaste recovery using Taguchi method and ANOVA. Polish Journal of Environmental Studies 3:1125-1131. doi: 10.15244/pjoes/30927

22. Chil-Chyuan K, Hsin-You L (2015) Dimensional accuracy optimization of the micro-plastic injection molding process using the Taguchi design method. Mater Sci Medziagotyra 2:244-248. doi: 10.5755/j01.mm.21.2.5864

23. Sun Y, Zuo D, Zhu Y, Li J (2013) Using Taguchi method to optimize polishing parameters in ice fixed abrasive polishing. Mater Manuf Process 28:923-927. doi:10.1080/10426914.2013.792419

24. Montgomery DC (2009) Design and analysis of experiments, 7th edn. John Wiley \& Sons, New Jersey, USA

25. Co HC (2008) Confirmation testing of the Taguchi methods by artificial neural-networks simulation. Int J Prod Res 17:46714685. doi:10.1080/00207540701213502

26. Chun-Liang L, Yi-Shun C, Yi-Hua L, Yeh-Hsiang H, Shu-Syuan H (2013) Optimization of a fuzzy-logic-control-based five-stage battery charger using a fuzzy-based Taguchi method. Energies 7:35283547. doi:10.3390/en6073528

27. Recioui A (2013) Application of hybrid Taguchi-genetic algorithm to the multiobjective design optimization of Yagi-Uda Atennas. Wirel Pers Commun 2:1403-1420. doi:10.1007/s11277-0120882-1

28. Recioui A, Bentarzi H (2013) Capacity optimization of MIMO wireless communications systems using a hybrid genetic-Taguchi algorithm. Wirel Pers Commun 2:1003-1019. doi:10.1007/s11277012-0857-2

29. Chao-Lieh Y, Kun-Tzu Y (2013) Multi-objective optimization of glass fiber cutting process by applying the fuzzy-based Taguchi method. Int J Reliab Qual Saf Eng 2:1-17. doi:10.1142/ S0218539313500083

30. Canessa E, Bielenberg G, Allende H (2014) Robust design in multiobjective systems using Taguchi's parameter design approach and a Pareto genetic algorithm. Revista Facultad de Ingeniería Universidad de Antioquia 72:73-86 